\title{
Resenha
}

\section{Avanço da Técnica e Afetação da Vida Privada no Espaço Público ${ }^{1}$}

\section{Marcos Catalan}

Pós-doutor pela Facultat de Dret da Universitat de BarceIona. Doutor summa cum laude em Direito pela Faculdade do Largo do São Francisco, Universidade de São Paulo. Mestre em Direito pela Universidade Estadual de Londrina. Coordenador-adjunto e professor no Mestrado em Direito e Sociedade da Universidade La Salle. Professor no curso de Direito da Unisinos. Visitor Research no Istituto Universitario di Architettura di Venezia. Professor visitante na Facultad de Derecho da Universidad de la República, Uruguai. Advogado parecerista. marcoscatalan@uol.com.br

EIDEM, Matías E. Afectación de la vida privada en la vía pública: vigilancia con cámaras de seguridad y restricción de derechos fundamentales. Buenos Aires: Ad Hoc, 2015. 192 p.

Recebido em: 10/1/2018

Aceito em: 25/1/2018

A publicação que aqui se busca sintetizar chegou às minhas mãos, quase sem querer, por ocasião de uma visita, não planejada, a uma pequenina livraria, tão despretensiosa quanto simpática, situada no coração da

1 Esta resenha foi alinhavada no âmbito do projeto de investigação científica A difusão de sistemas de videovigilância e a tutela de direitos densificadores de liberdade e igualdade no Brasil. A pesquisa é financiada pela Universidade La Salle. 
América Central. Era maio, talvez junho de 2017, quando, ao caminhar pelas ruas de San José à procura da Corte Interamericana de Direitos Humanos e, embora, ainda deveras distante dela - soube-o mais tarde -, busquei abrigar-me da chuva que, ao aproximar-se a galope, trazia consigo, além do risco de eletrocussão, a promessa de amenizar um pouco o calor que parecia estar sendo soprado diretamente das profundezas do Hades.

O livro é interessante; a temática que explora, deveras atual.

Sua leitura é necessária, melhor, imprescindível a todo aquele que investiga ou, simplesmente, se interessa por temas afetos (a) aos direitos de personalidade, em especial intimidade, privacidade, captura, armazenamento, utilização e proteção de dados sensíveis; (b) às liberdades civis, à igualdade substancial e as ferramentas e mecanismos utilizados para atribuir-lhes densidade dogmática e hermenêutica; (c) à teoria dos direitos fundamentais; e, ainda, não se pode deixar de apontar, (d) ao universo dos direitos humanos, aqui pensados, enquanto direitos de resistência.

Antecipo, enfim, neste singelíssimo introito, que uma manhã ou tarde serão mais que suficientes para que os olhos do leitor ou da leitora possam percorrer, de forma minudente e cuidadosa, a rica análise feita de forma clara e objetiva pelo cientista sul-americano, acerca dos efeitos provocados, no âmbito da vida privada, pela difusão dos sistemas de videovigilância e controle que se espalham pela urbe contemporânea.

Uma nota formal: Matías Eidem é mestre em Direito Penal pela Universidade Austral, situada em Buenos Aires.

Três partes, sete capítulos - nove, se computadas a introdução e a conclusão - fundem-se nas 111 páginas que dão vida ao livro aqui resenhado por um pesquisador que assume, como de hábito, a culpa, toda e qualquer culpa, pelos eventuais equívocos havidos no processo de decodi- 
ficação das ideias gestadas pelo investigador portenho. É importante, ainda, que não nos esqueçamos de informar a existência de outras cinco deliciosas laudas que foram alinhavadas por ocasião do interessantíssimo prefácio grafado e assinado pelo professor Javier Augusto de Luca, orientador da Dissertação de Mestrado que, ao ser lapidada não tenho, confesso, como precisar, quantas vezes mais, veio até mim, sob a forma do atraente livro que busco, aqui, criticamente, sintetizar.

\section{$* * *$}

A primeira parte da obra publicada compõe-se a partir da justaposição de outras três.

As palavras lançadas nas primeiras páginas do texto procuram demonstrar - tendo por lastro vasta e interessante bibliografia -, que o surgimento e a expansão dos sistemas de videovigilância e controle estão, intimamente, conectados (a) à cultura do medo e (b) à análise econômica do direito.

Consoante esclarece o autor, o campo de análise teórica da cultura do medo permite identificar algumas das relações existentes entre (a) a necessidade crescente de difusão de segurança, melhor, da sensação, da percepção subjetiva de segurança pela comunidade e, quer me parecer, pelos consumidores e eleitores, não necessariamente nessa ordem; (b) os discursos construídos e disseminados, pelo Mercado e pela Política, com este escopo; e, ainda, (c) os movimentos que podem ser mapeados, em concreto, enquanto ações que buscam estimular a referida percepção, ${ }^{2} o$ uso de hardwares e softwares e a irritação que provocam em alguns dos

${ }^{2}$ CATALAN, Marcos. The diffusion of the video surveillance system in the contemporary urbe: Argus Panoptes, electronic brains and their connections with the violation of liberties and equalities. In: ACHUTTI, Daniel; BONINI, Emanuela; VANIN, Fabio (Org.). Reducing Boundaries: understanding exclusion through security defensive systems in wealthy urban areas. Szczecin: Mimesis International, 2017. p. 223-237. V. 1. 
diques erigidos ao longo da História recente da humanidade, visando à contenção dos desmandos do Leviatã e, também, a manifesta e perceptível legitimação da omissão estatal.

La concepción sobre la vigilancia ha conseguido una nueva formulación, despojada de valoraciones negativas e imponiéndose como necesaria para lograr un buen gobierno. ${ }^{3}$ En términos abstractos, se podría afirmar que la vigilancia consiste en observar, velar, poner atención y custodiar. Ahora bien, en el contexto que se analiza, debe entenderse como una forma de ejercer control social para sentirse seguros, que aprovecha y utiliza todo lo que tiene a su alcance, como las innovaciones tecnológicas modernas [sic]. En consecuencia, se ha modificado el rol de quien vigila, se ha disminuida la presencia policial en las calles - más costosa y nociva al diseño urbano -, y aumentado el personal a cargo del control de las cámaras de seguridad, micrófonos y dispositivos de rastreo. ${ }^{4}$

Da análise econômica do direito, por sua vez, deriva a ligação dos sistemas de videovigilância com a técnica da prevenção situacional do delito e a correlata pretensão teórica de obstaculizá-los, de evitar os delitos, atuando preventivamente - importando, menos, os efeitos colaterais provocados $^{5}$-, em vez de recorrer a ferramentas com atuação ex post atada à dimensão simbólica que parece envolver as respostas, tradicionalmente,

${ }^{3}$ AGUSTINA, José. Prevención del delito en la empresa: límites ético-jurídicos en la implementación de sistemas de videovigilancia. In: Tendencias en prevención del delito y sus límites. Buenos Aires: BdeF, 2010. p. 93.

${ }^{4}$ EIDEM, Matías E. Afectación de la vida privada en la vía pública: vigilancia con cámaras de seguridad y restricción de derechos fundamentales. Buenos Aires: Ad Hoc, 2015. p. 37.

${ }^{5}$ LUCA, Javier Augusto de. Prólogo. In: EIDEM, Matías E. Afectación de la vida privada en la vía pública: vigilancia con cámaras de seguridad y restricción de derechos fundamentales. Buenos Aires: Ad Hoc, 2015. p. 15-16. "Se trata de la vigilancia de los movimientos de un grupo mayor de personas, ya no de procesados o culpables de la comisión de delitos, sino de todos los habitantes. Como se ve, tal implicación no es inocua ni inocente. Significa nada más ni nada menos que el salto de la justicia represiva a la preventiva, del objeto del derecho penal al del viejo derecho de policía, de la aplicación de sistemas de control de modalidades de pena o de medidas alternativas a la pena, al control de las actividades comunes y diarias de todos nosotros, sin siquiera la sospecha de la comisión de un delito y, todo ello, bajo criterios de defensa social, de seguridad ciudadana". 
dadas pelo direito penal. Em tal cenário, depois de relatar que, consoante a referida matriz teórica, aqueles que pensam em praticar um ilícito internalizariam ao menos três âmbitos de reflexões: a possibilidade (ou não) de êxito, os benefícios, potencialmente, atados à conduta a ser praticada $\mathrm{e}$, enfim, como impedir a gênese ou apagar a existência de rastros que permitiriam ligar ação e agente, pondera-se, com lastro em Clarke e Felson, ${ }^{6}$ que

los principales problemas que se han esgrimido contra la prevención situacional del delito se vinculan con: su acotado campo de análisis, debido a que ofrece una respuesta irrelevante al fenómeno de la inseguridad; deja de lado la culpabilidad moral; no aprehende las causas reales de delito; no se preocupa por la justicia social, las libertades civiles y la privacidad; desplaza el delito hacia otros sectores que carecen de los medios para reducir las oportunidades de su comisión; solo sirve para cierta clase de hechos; $y$, finalmente, lleva a la persona a elaborar un plan de mayor complejidad para eludir los obstáculos preventivos, con la posibilidad de que provoque un mayor daño. ${ }^{7}$

Acerca do tema, conforme pinçado no livro, merece destaque, ainda, o fato de que

Como se sabe desde hace muchos años, este método estilo Panóptico benthamiano o de gran hermano orwelliano no hace mejor a las personas, no modifica conductas por propio convencimiento, sino que solo opera [cuando opera] sobre las mentes de las personas que conocen de su existencia y por el temor a ser descubierto en una actitud antisocial, es decir, una fachada de buen ciudadano al saberse controlado. ${ }^{8}$

${ }^{6}$ CLARKE, Ronald; FELSON, Marcus. Cuestiones éticas en torno de la prevención situacional del delito. In Tendencias en prevención del delito y sus límites. Buenos Aires: BdeF, 2010. p. 176.

${ }^{7}$ EIDEM, Matías E. Afectación de la vida privada en la vía pública: vigilancia con cámaras de seguridad y restricción de derechos fundamentales. Buenos Aires: Ad Hoc, 2015. p. 43.

8 LUCA, Javier Augusto de. Prólogo. In: EIDEM, Matías E. Afectación de la vida privada en la vía pública: vigilancia con cámaras de seguridad y restricción de derechos fundamentales. Buenos Aires: Ad Hoc, 2015. p. 15-17. 
Ato contínuo, cuidadosamente, o autor passa a rabiscar os detalhes de um mapa conceitual delineado na tentativa de explicar aos leitores, em perspectiva estática e dinâmica, como operam os sistemas de videovigilância e controle, fazendo-o, aliás, com admirável, quase irritante, riqueza de minúcias, para, uma vez finda esta tarefa, poucas páginas adiante, delinear, também, o espaço geográfico no qual seres humanos experimentam, quase sempre passivamente, suas preocupações teóricas, algumas delas, aliás, contextualizadas com precisão por ocasião do prefácio, como se percebe na passagem que afirma que muitos, talvez, muitos de nós,

viven en barrios cerrados con cámaras de seguridad que lo controlan todo, se dejan revisar los baúles de los automóviles, le piden identificación a propios y extraños y, todo eso, en manos de agencias de seguridad privadas cuyos titulares y empleados, y sus antecedentes, son totalmente desconocidos. De haber dado la vida por las libertades, las hemos cedido todas graciosamente. ${ }^{9}$

Curiosamente, o pesquisador exclui, intencionalmente é fato, do âmbito de sua análise, os espaços privados abertos ao público, nas hipóteses nas quais, tais espaços, comportem quaisquer espécies de restrições à entrada e/ou trânsito de pessoas - barreiras que vão de portas à exigência de bilhetes -, bem como, igualmente, exclui de seu campo de análise teórica, os ambientes públicos de titularidade do poder público, portanto, os espaços públicos que possuam as características físicas e/ou simbólicas salientadas há pouco. Grafo, propositalmente o curiosamente, pois o argumento utilizado para o corte metodológico havido parece atado à percepção de que praças e parques, ruas e avenidas são locais nos quais

${ }^{9}$ LUCA, Javier Augusto de. Prólogo. In: EIDEM, Matías E. Afectación de la vida privada en la vía pública: vigilancia con cámaras de seguridad y restricción de derechos fundamentales. Buenos Aires: Ad Hoc, 2015. p. 16. 
"donde uno sabe que es visto, pero se pierde en el anonimato que envuelve el flujo continuo de gente transitando", ${ }^{10}$ espaços, portanto, nos quais "uma multidão não é companhia”. ${ }^{11}$

Fica a questão: Aqueles que transitam por rodoviárias e estações de trens, cassinos ou shoppings, cinemas e teatros, universidades ou prostíbulos poderão, então, ter seu dia a dia devassado, percebendo ou não, por seres eletrônicos afortunados com mais olhos que Argus Panoptes e com memórias, infinitamente, mais espaçosas que a de Mnemosine?

A seletividade e a segregação fundidas aos CCTVs também foram objeto de interessantes digressões. Salienta o autor que as câmeras costumam ser instaladas em bairros nos quais vivem e (ou) trabalham pessoas dignas de proteção, ${ }^{12}$ o que provocaria a estigmatização, bem como excluiria, do pequeno âmbito de proteção alcançado em concreto - quando do recurso a esses sistemas - os que vivem em áreas urbanas não abraçadas pela vigilância eletrônica.

É oportuno anotar, enfim, que o terceiro pilar de sustentação do trabalho busca delinear os contornos dados pelo Direito à vida privada. Emergem, nessa parte da obra, inúmeras referências normativas capturadas no âmbito do direito argentino e na esfera do direito internacional. Há, ainda, alusão a diversos e interessantes julgados recortados nos alfarrábios da Corte Interamericana de Direitos Humanos e da European Court of Human Rights.

\footnotetext{
${ }^{10}$ EIDEM, Matías E. Afectación de la vida privada en la vía pública: vigilancia con cámaras de seguridad y restricción de derechos fundamentales. Buenos Aires: Ad Hoc, 2015. p. 49.

${ }^{11}$ GOETHE, Johann Wolfgang Von. Os sofrimentos do jovem Werther. São Paulo: Nova Alexandria, 2011.

${ }^{12}$ Eis um belo cenário para a pesquisa empírica.
} 
Afere-se, ademais, nessa parte do livro, a aparente preocupação do pesquisador em vincular a vida privada e a proteção de dados aos direitos humanos, talvez - e isso não é claro no texto - buscando chamar a atenção para a universalidade do tema que se propõe a investigar. Entremeio a tais páginas e seu especial colorido teórico, é possível encontrar uma chave deveras importante para a decodificação da mensagem que a publicação busca difundir, pois,

la exposición a miradas casuales es inevitable y cotidiana, sin embargo, generalmente duran intervalos sumamente pequeños, se pierden en el olvido, entre la inmensa cantidad de personas que circulan: a lo sumo, podrá recordarse en una anécdota, pero a no ser que quién la cuente la haya registrado con algún dispositivo, jamás se reproducirá en términos tales que impliquen cierta individualización [y] la clave que hallamos en la convención social que acepta la observación por parte de terceros de manera fortuita y momentánea en la vía pública, sin que ello implique perder el carácter de anónimo, oculto y desconocido, ${ }^{13}$

que marca o ser que é observado, ante à incontestável impossibilidade de não vir a sê-lo.

O segundo capítulo, igualmente dividido em três partes, busca acoplar, entrelaçar, fundir, sobrepor alguns dos riscos e desvios antevistos na captura, registro, tratamento, armazenamento e exposição de cada um dos incomensuráveis momentos que possam compor a vida privada - a existência humana, em sua dimensão privada, portanto - por sistemas de videovigilância.

Suas linhas têm como premissas as percepções de que (a) "la mayor parte del contenido comprendido en las grabaciones exhibe conductas cotidianas y ordinarias”, passíveis, portanto, de proteção jurídica e, ainda, de que

${ }^{13}$ EIDEM, Matías E. Afectación de la vida privada en la vía pública: vigilancia con cámaras de seguridad y restricción de derechos fundamentales. Buenos Aires: Ad Hoc, 2015. p. 72. 
(b) "el observador es inobservable, es decir, constituye un control unilateral, y el único conocimiento [cuando adecuadamente informado] se vincula con la posibilidad de ser vigilado" ${ }^{14}$

É preciso registrar que, durante seu desvelar, o investigador portenho revisita as molduras que havia esboçado outrora, com traço firme e seguro. Ao buscar, entretanto, aparentemente, atribuir-lhes maior, talvez melhor colorido, usa tons deveras fastidiosos, exagerando na compilação e transcrição de um número bastante cansativo de regras que colhe nas páginas reais e virtuais (a) da Convenção Americana sobre Direitos Humanos (CADH); (b) do Pacto Internacional de Direitos Civis e Políticos (PICDP); (c) nos Princípios de Siracusa e, ainda; (d) da Constitución de la Nación Argentina $(\mathrm{CN})$, bem como de excertos de decisões recortadas nos repositórios (e) da Corte Interamericana de Direitos Humanos (CIDH); (f) da European Court of Human Rights (CEDH); e, enfim, (g) da Corte Suprema de Justicia de la Nación argentina (CSJN).

Que o leitor não espere um gran finale, tampouco, apoteótica crítica.

Àqueles que como eu o esperavam, tenho a informar que o gosto amargo da submissão, da domesticação, ficará na boca, como fel, por algum tempo. O capítulo em pauta definha com sugestões dogmáticas acerca (a) da montagem das câmeras; (b) das informações que hão de ser publicizadas e difundidas e, perante a comunidade, acerca da existência e operação do sistema de videovigilância -; (c) do tratamento técnico que inclui, criptografia assimétrica, forma e tempo de armazenamento, proteção de dados sensíveis e aniquilamento dos dados, por exemplo -; e, enfim, (d) do acesso, aos eventuais interessados, aos dados compilados.

${ }^{14}$ EIDEM, Matías E. Afectación de la vida privada en la vía pública: vigilancia con cámaras de seguridad y restricción de derechos fundamentales. Buenos Aires: Ad Hoc, 2015. p. 79-83. 
O último capítulo - que mui facilmente poderia integrar o segundo, pois é grafado sobre singelas sete laudas - limita-se a reproduzir e, superficialmente, anotar, alguns dispositivos das leis que versam sobre a videovigilância na Cidade Autônoma de Buenos Aires. Dispensa, portanto, além da crítica metodológica registrada na interpolação registrada anteriormente, quaisquer outras notas.

O livro, mesmo com os diminutos problemas apontados, é leitura a ser feita pelos estudiosos do Direito que se interessam por temas que tocam, de algum modo, a vida privada. Pesquisadores que investigam os direitos civis, os direitos fundamentais e os direitos humanos, sem dúvida, estão entre eles.

Por fim e, antes que o labor de Chronos impeça que este texto se transforme, ainda que minimamente, incorporando reflexões que não foram devidamente ruminadas ou venha a sofrer com a amputação de excessos não percebidos por meus olhos míopes - e quase sempre filtrados por gentis e dedicados estudantes da Graduação e do Mestrado, meninas e meninos com quem dialogo frequentemente e que tanto me auxiliam nos cruéis instantes que antecedem o envio dos textos para a edição e publicação -, registro que a tradução para o português da obra de Matías Eidem é bastante oportuna, pois, no mínimo, permitirá a um sem número de pesquisadores que compartilham nosso vernáculo, embora não leiam o espanhol, leiam-no e possam meditar acerca da expansão dos sistemas eletrônicos de vigilância e controle na urbe contemporânea.

San Cesareo, janeiro de 2018.

Imerso na quietude, aquecido pelo frio acolhedor e inebriado com a beleza que brota nas infinitas e mutantes paisagens alvas no inverno do Lazio. 